\title{
Penerapan Model Pembelajaran Heuristic Vee Terhadap Peningkatan Pemahaman Konsep Siswa Pada Materi Fluida Statis
}

\author{
Irma Suryani $^{1}$, Riski Muliyani ${ }^{1}$ \\ 1,2Program Studi Pendidikan Fisika, STKIP Singkawang \\ e-mail: \\ 1irmassuryani770@gmail.com \\ 2kikiriski1012@gmail.com
}

\begin{abstract}
.
This study aims to get description of the increasing aspects of students' conceptual understanding after applying beuristic vee learning models to static fluid material. The research used is quantitative research, with the weak experiment design method with the design of one group pretest-posttest design. Data collection techniques used was tests and non-tests. The test instruments were in the form of pre-test and post-test concepts. While the non-tests were in the form of model implementation observation sheets and student response sheets. The samples taken in this study were cluster sampling which was chosen by one class from all eighth grade students. The population in this study was class VIII of SMP Negeri 8 Singkawang with a total of 32 students. The results showed that the heuristic vee learning model could improve students' conceptual understanding of the interpreting aspect by 0.7 with high categories, the classifying aspects by 0.3 with moderate categories, the concluding aspects by 0.6 with moderate categories; aspects comparing with moderate categories and aspects explained by 0.2 with low categories.
\end{abstract}

Keywords: heuristic vee, student concept understanding, static fluid

\begin{abstract}
ABSTRAK.
Penelitian ini bertujuan untuk mendapatkan gambaran mengenai peningkatan aspek pemahaman konsep siswa setelah diterapkan model pembelajaran beuristic vee pada materi fluida statis. Penelitian yang digunakan adalah penelitian kuantitatif, dengan metode weak experiment design dengan desain one group pretest-posttest design. Teknik pengumpulan data yang digunakan adalah tes dan non tes. Instrumen tes berupa soal pre-test dan post-test pemahaman konsep. Sedangkan non tes berupa lembar observasi keterlaksanaan model dan lembar respon siswa. Sampel yang diambil dalam penelitian ini berupa Cluster sampling yang dipilih satu kelas dari seluruh siswa kelas VIII. Populasi dalam penelitian ini adalah kelas VIII SMP Negeri 8 Singkawang dengan jumlah 32 siswa. Hasil penelitian menunjukkan bahwa model pembelajaran heuristic vee dapat meningkatkan pemahaman konsep siswa pada aspek menafsirkan sebesar 0,7 dengan ketegori tinggi, aspek mengklasifikasikan sebesar 0,3 dengan ketegori sedang, aspek menyimpulkan sebesar 0,6 dengan ketegori sedang,; aspek membandingkan dengan ketegori sedang dan aspek menjelaskan sebesar 0,2 dengan ketegori rendah.
\end{abstract}

Kata Kunci: heuristic vee, pemahaman konsep siswa, fluida statis 


\section{PENDAHULUAN}

Pemahaman konsep sangat penting dalam proses belajar karena tingkat capaian hasil belajar siswa pada taksonomi versi Anderson menjadi dasar struktur kognitif yang kuat agar mampu menyimpan informasi yang telah diselediki kapan saja dengan jangka waktu yang lebih lama (Muliyani, 2018).

Pentingnya memahami konsep bertujuan agar siswa dapat mengaitkan konsep yang satu dengan yang lain, mampu menerapkan konsep dan mampu mengevaluasi tugas yang telah dikerjakan. Siswa terkadang mampu menjawab sebuah pertanyaan namun tidak mampu menjawab konsep yang sama dengan redaksi pertanyaan yang tidak sama. Dengan kata lain, siswa tidak memiliki pemahaman konsep yang mendalam (Nawati, Saepuzaman, \& Suhandi, 2017).

Pemahaman konsep merupakan kemampuan siswa untuk mengerti suatu konsep mengenai fenomena sehari-hari berdasarkan pengalaman dan pengamatan yang kemudian akan dihubungkan dengan konsep yang sebelumnya telah ada pada mereka (Anderson, W.L \& Krathwohl, 2010). Anderson dan Krathwohl (2010) juga mengungkapkan bahwa siswa memahami konsep ketika mereka menghubungkan pengetahuan baru dan pengetahuan lama serta mampu mengkontruksi makna dari pembelajaran baik dalam bentuk tulisan, lisan maupun gambar, yang disampaikan melalui pembelajaran langsung maupun media. Dari definisi tersebut, dapat disimpulkan pemahaman konsep merupakan kemampuan menangkap pengertian-pengertian seperti mampu mengungkapkan suatu materi yang disajikan kedalam bentuk yang lebih dipahami baik dalam bentuk tulisan, lisan maupun gambar. Pemahaman konsep yang dimiliki oleh siswa dapat digunakan untuk menyelesaikan suatu permasalahan yang ada kaitan dengan konsep yang dimiliki.

Masalah rendahnya pemahaman konsep siswa perlu dicari solusinya agar pembelajaran yang dilakukan dapat mencapai hasil yang maksimal dan mampu meningkatkan pemahaman konsep siswa. Maka perlu suatu model pembelajaran yang mampu memberikan kesempatan kepada siswa berdasarkan pengalaman nyata yang dimiliki oleh siswa, sehingga pembelajaran akan menjadi lebih efektif. Model pembelajaran heuristic vee merupakan model pembelajaran yang membantu siswa untuk menghasilkan pengetahuan baru, memahami struktur pengetahuan, bagaimana pengetahuan dibangun dan dapat memperdalam pemahaman konsep siswa. Heuristic vee dapat diartikan sebagai salah satu cara menyajikan bahan pembelajaran dalam bagan berbentuk huruf "V" dengan menuangkan pengetahuan awal yang kemudian dikaitkan dengan pengetahuan selanjutnya yang dituangkan secara lebih terperinci berupa pengonstruksian pengetahuan awal dengan pengetahuan barunya (Suhyanto dan Musyrifah, 2016: 48).

Heuristic vee terdiri dari dua aspek yaitu aspek konseptual dan aspek metodologi yang membantu siswa untuk mempengaruhi dan mengkontruksi pengetahuan baru siswa (Rahmawati, 2018). Pada model pembelajaran heuristic vee terdapat lima tahapan yaitu orientasi, pengungkapan gagasan atau pengungkapan konsep, pengungkapan permasalahan atau pertanyaan fokus, pengontruksian pengetahuan baru, dan evaluasi (Sucipta, Suastra, \& Sadia, 2014). Pada tahap pengkonstruksian pengetahuan baru merupakan salah satu tahap pada model heuristic vee yang dapat meningkatkan pemahaman konsep siswa. Dalam pembelajaran model heuristic vee, siswa dilibatkan secara aktif untuk mengkonstruk pengetahuannya sendiri. Selain itu, menurut Rahmawati (2018: 24) model pembelajaran heuristic vee mengacu kepada pembelajaran bermakna dan konstruktivisme yang membantu siswa membangun konsep-konsep atau prinsip-prinsip dalam proses berpikir untuk menghasilkan pengetahuan baru dan memperdalam pemahaman konsep. Diagram V membantu menemukan bahwa makna dari seluruh pengetahuan pada akhir berasal dari kejadian atau objek yang diamati. 
Pada setiap tahapan model heuristic vee yang dilatihkan mengalami peningkatan pemahaman konsep disetiap aspeknya. Disetiap tahapan model heuristic vee yang dilatihkan siswa diberikan beberapa pertanyaan atau permasalahan yang berkaitan dengan materi fluida statis untuk mengetahui sejauh mana tingkat pemahaman siswa dan juga melatihkan siswa untuk mengungkapkan gagasan atau konsep awal yang mereka miliki.

Berdasarkan hal tersebut, maka penelitian ini bertujuan untuk mendapatkan gambaran mengenai peningkatan aspek pemahaman konsep siswa setelah diterapkan model pembelajaran beuristic vee pada materi fluida statis dan untuk mendapatkan gambaran mengenai respon siswa terhadap model pembelajaran beuristic vee pada materi fluida statis.

\section{METODOLOGI}

Penelitian ini merupakan penelitian yang bertujuan untuk mendeskripsikan konsep fluida statis pada siswa kelas VIII SMP Negeri di Kota Singkawang. Konsep fisika yang diteliti dibatasi pada materi fluida statis. Penelitian ini termasuk penelitian kuantitatif yang mendeskripsikan fakta, fenomena yang terjadi pada subyek penelitian dengan metode weak experiment design. Metode weak experimental design merupakan metode eksperimen yang tidak mempunyai variabel kontrol.

Desain penelitian yang digunakan pada penelitian ini adalah desain one group pretest-posttest design. Desain ini mencakup satu kelompok yang diobservasi pada tahap pre-test kemudian dilanjutkan dengan treatment dan post-test (Creswell, 2009). Sampel dalam penelitian diberi perlakuan (treatment) yaitu penerapan model heuristic vee terhadap pemahaman konsep siswa selama waktu tertentu. Pelaksanaan pre-test dilakukan sebelum pemberian treatment, dan post-test dilaksanakan setelah treatment. Desain penelitian dapat dilihat pada Tabel 1. Sebagai berikut.

Tabel 1. Desain Penelitian One Group Pretest-Posttset Design

\begin{tabular}{ccc}
\hline Pre-Test & Treatment & Post-Test \\
\hline $\mathrm{O}$ & $\mathrm{X}$ & $\mathrm{O}$ \\
\hline
\end{tabular}

Keterangan:

O : Tes Pemahaman Konsep

$\mathrm{X} \quad$ : Treatment menggunakan model beuristic vee

Populasi dalam penelitian adalah seluruh siswa kelas VIII SMP Negeri di Kota Singkawang. Sampel dalam penelitian ini dipilih satu kelas dari seluruh siswa kelas VIII di SMP Negeri Kota Singkawang. Adapun teknik pengambilan sampel dalam penelitian ini adalah cluster sampling. Teknik penarikan sampel dengan menggunakan metode ini, populasi dibagi terlebih dahulu atas kelompok berdasarkan area atau cluster, lalu beberapa cluster dipilih sebagai sampel, dari cluster tersebut diambil seluruh atau sebagian saja untuk dijadikan sampel, anggota populasi di setiap cluster tidak perlu homogen.

Teknik pengumpulan data yang digunakan dalam penelitian ini adalah tes dan non tes. Tes pemahaman konsep digunakan untuk mengukur peningkatan kemampuan pemahaman konsep siswa pada materi fluida statis. Bentuk tes yang digunakan pada tes awal (pretest) dan tes akhir (posttest) adalah sama. Pemberian pretest bertujuan untuk melihat kemampuan siswa sebelum mendapatkan perlakuan (treatment) kegiatan pembelajaran bermodel heuristic vee. Sedangkan posttest diberikan untuk melihat hasil yang dicapai siswa setelah mendapatkan perlakuan (treatment). Tes pemahaman konsep berbentuk pilihan ganda sebanyak 15 soal dengan 4 pilihan (A, B, C dan D). Tes ini mengukur aspek menafsirkan, mengklasifikasikan, menyimpulkan, membandingkan, dan menjelaskan, dimana setiap aspek tersebut tersebar merata. 
Non tes yang digunakan pada penelitian ini berupa skala sikap dan lembar keterlaksanaan model. Pengumpulan data berupa lembar observasi yang digunakan pada saat model pembelajaran diterapkan. Lembar observasi akan diberikan kepada observer ditempat penelitian. Pengambilan data dengan skala sikap dilaksanakan setelah diterapkan model pembelajaran heuristic vee yang diberikan kepada sampel. Lembar ini berisi pernyataan positif dan pernyataan negatif. Skala pengukuran yang digunakan adalah skala likert yaitu setuju dan tidak setuju. Untuk pengisian lembar respon, siswa memberikan tanda check list $(\sqrt{ })$ sesuai dengan pernyataan yang dipilih oleh siswa.

Peningkatan pemahaman konsep siswa setelah mengikuti pembelajaran model heuristic vee dihitung berdasarkan skor gain yang ternormalisasi dengan rumus yang dikembangkan oleh (Hake, 1998).

$$
\langle g\rangle=\frac{S_{\text {post-test }}-S_{\text {pre-test }}}{S_{\text {maksimum }}-S_{\text {pre-test }}}
$$

Keterangan:

$$
\begin{array}{ll}
\langle g\rangle & \text { : gain ternormalisasi } \\
S_{\text {post-test }} & \text { : skor tes akhir } \\
S_{\text {pre-test }} & \text { : skor tes awal } \\
S_{\text {maksimum }} & \text { : skor maksimum dari skor tes awal dan skor tes akhir }
\end{array}
$$

Kategori peningkatan gain yang dinormalisasi (n-gain) untuk menyatakan peningkatan kemampuan pemahaman konsep siswa pada materi fluida statis dapat disajikan pada Tabel. 3.

Tabel 3. Kategori Peningkatan Pemahaman Konsep Siswa

\begin{tabular}{cc}
\hline Gain & Kategori \\
\hline$(\mathrm{g}) \geq 0,7$ & Tinggi \\
\hline $0,3 \leq(\mathrm{g})<0,7$ & Sedang \\
\hline$(\mathrm{g})<0,3$ & Rendah \\
\hline
\end{tabular}

\section{TEMUAN DAN PEMBAHASAN}

Berdasarkan hasil analisis data yang diperoleh dari penelitian diungkapkan bahwa pemahaman konsep siswa setelah dinormalisasi dengan uji $\mathrm{N}$-gain diperoleh peningkatan pada setiap aspeknya. Pada aspek menafsirkan sebesar 0,7 dengan kategori tinggi, aspek mengklasifikasikan 0,3 dengan kategori sedang, aspek menyimpulkan 0,6 dengan kategori sedang, aspek membandingkan 0,5 dengan kategori sedang dan aspek menjelaskan 0,2 dengan kategori rendah. Untuk lebih jelasnya dapat dilihat pada grafik berikut 


\section{Peningkatan Pemahaman Konsep Siswa}

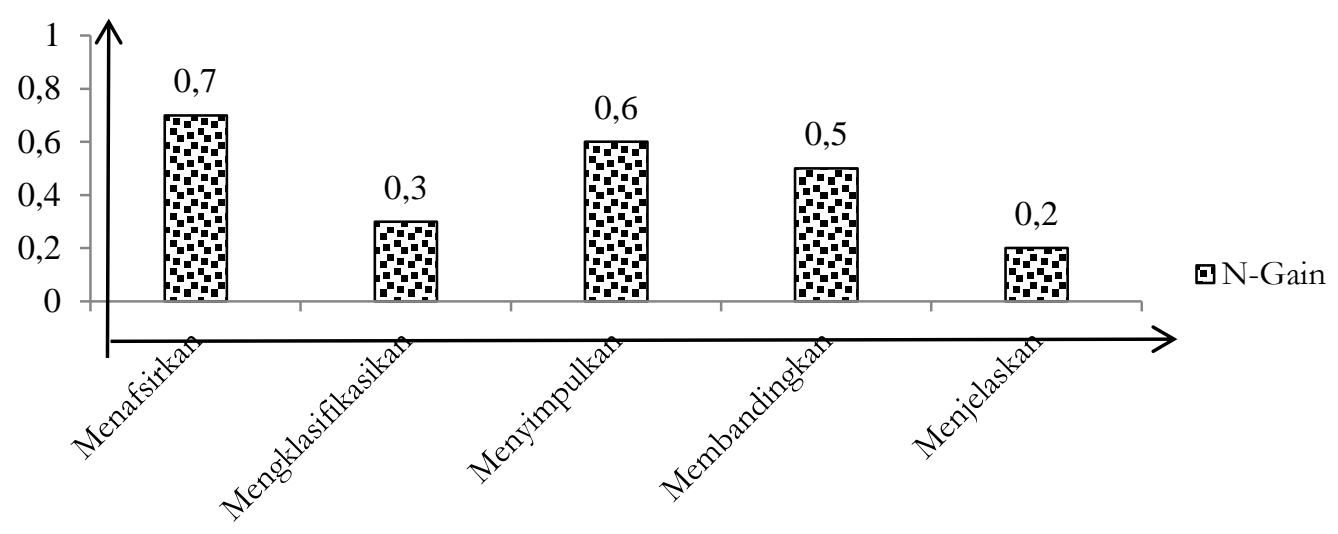

\section{Gambar 1. Skor n-gain aspek pemahaman konsep siswa}

Berdasarkan Gambar 1. tampak bahwa pemahaman konsep siswa pada aspek menjelaskan berkategori rendah. Rendahnya pemahaman konsep pada aspek menjelaskan disebabkan beberapa faktor yaitu: a) siswa kurang percaya diri dalam mengemukakan pendapat atau gagasan konseptual yang dimilikinya, b) siswa kurang aktif dalam berdiskusi, c) tingkat kemudahan soal, d) tingkat pemahaman konsep setiap siswa berbeda. Kesulitan dalam mengemukakan pendapat diduga terjadi salah satunya dari rendahnya kemauan siswa dalam mencatat seluruh informasi yang dihadirkan melalui fenomena (Kurniawan, 2018). Selain itu, faktor tingkat kemudahan soal serta pemahaman saling terkait. Tingkat kemudahan yang bervariasi tentu dan tingkat pemahaman siswa yang berbeda tiap individu dapat menjadi factor penyebab hasil capaian indikator tidak sesuai ekspektasi (Radiko, Kurniawan, \& Muliyani, 2018). Pernyataan ini dapat dimaknai bahwa soal-soal yang tergolong sukar cenderung akan sulit diselesaikan oleh siswa yang memiliki pemahaman/ berkemampuan rendah.

Pada aspek mengklasifikasikan dan aspek menjelaskan peningkatan $N$-gain hanya sebesar 0,3 dan 0,2 dengan persentase sebesar 91\% dan 84\% dengan kategori sangat baik. Pada aspek mengklasifikasikan dan aspek menjelaskan ada beberapa siswa yang menjawab salah dan pada lembar responnya juga menunjukkan respon negatif. Salah satunya siswa dengan kode B12 tidak bisa menjawab soal pada aspek mengklasifikasikan dan aspek menjelaskan. Dibuktikan dengan nilai posttest dan lembar respon siswa yang juga merespon negatif, sebagai contoh jawaban siswa nomor kode B12 pada aspek mengklasifikasikan terlihat pada Gambar 2.

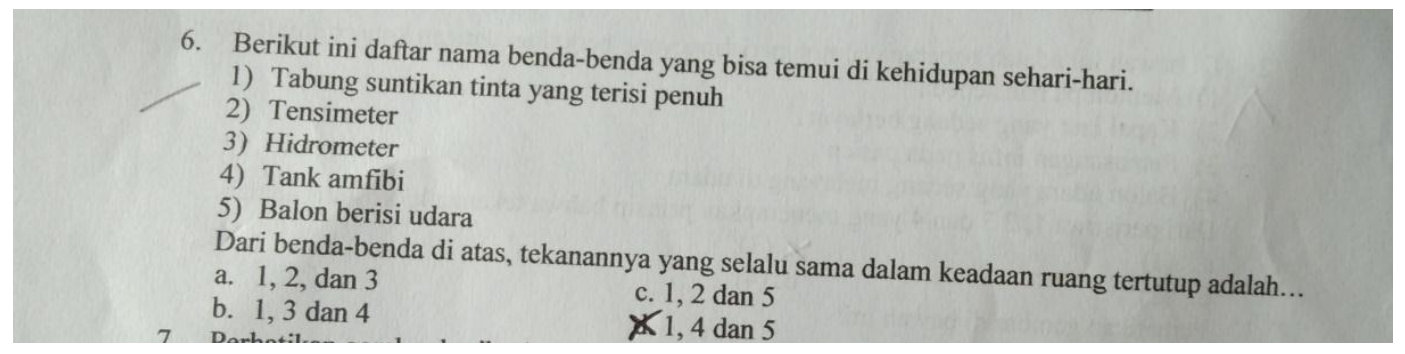

\section{Gambar 2. Sampel jawaban siswa kode B12 soal mengklasifikasikan yang salah.}

Contoh sampel jawaban soal mengklasifikasikan yang benar terlihat pada Gambar 3 sebagai berikut. 
6. Berikut ini daftar nama benda-benda yang bisa temui di kehidupan sehari-hari.

1) Tabung suntikan tinta yang terisi penuh

2) Tensimeter

3) Hidrometer

4) Tank amfibi

5) Balon berisi udara

Dari benda-benda di atas, tekanannya yang selalu sama dalam keadaan ruang tertutup adalah..

a. 1,2 , dan 3

b. 1, 3 dan 4

X. 1,2 dan 5

Gambar 3. Sampel jawaban soal mengklasifikasikan yang benar

Contoh sampel respon siswa kode B12 terlihat pada Gambar 9 sebagai berikut.

\begin{tabular}{|l|l|l|}
\hline 3 & $\begin{array}{l}\text { Pembelajaran saat ini membuat saya mampu } \\
\text { mengelompokkan penerapan konsep-konsep fisika } \\
\text { dalam kehidupan sehari-hari. }\end{array}$ & $\checkmark$ \\
\hline
\end{tabular}

Gambar 4. Sampel respon siswa kode B12

Pembelajaran menggunakan model heuristic vee pada materi fluida statis dinyatakan dapat meningkatkan pemahaman konsep siswa, siswa merespon dengan baik kegiatan pembelajaran. Hal ini ditunjukkan dengan hasil analisis respon siswa sebesar 92\% dengan kategori positif. Data ini didukung pula oleh Ramnarain \& Mossa (2017) bahwa skenario pembelajaran yang dirancang dengan aktivitas tertentu untuk mencapai tujuan pembelajaran, maka akan didapatkan hasil pengukuran yang sesuai. Faktor lain yang terkait misalnya kemampuan meng-analogi-kan konsep oleh guru. Pola pembelajaran ini sesuai dikarenakan siswa beralih dari pendidikan dasar menuju pendidikan menegah dimana akan diperkenalkan konsep secara abstrak dan kompleks (Suleyman, 2016).

Proses ini juga melibatkan guru dimana pertanyaan arahan yang dilontarkan mampu menuntun siswa untuk berpikir lebih jauh sehingga terpancing untuk menemukan jawabannya sendiri (Evriani, Kurniawan, \& Muliyani, 2017). Selain itu, pengetahuan yang dimiliki oleh siswa juga berperan terhadap tingginya aspek menafsirkan pada penelelitian ini. Pengetahuan yang diperoleh seseorang dimana pengetahuan itu dapat diterapkan pada proses pengolahan informasi baru atau bahkan sama persis maka proses asimiliasi semakin lancar. Dampaknya, siswa akan sangat mudah menerima ilmu baru (Muliyani, 2018).

Perbedaan pemahaman konsep siswa disebabkan kemampuan individu siswa yaitu kemampuan inteleksual siswa, kamampuan fisik, latar belakang keluarga, kebiasaan dan pendekatan belajar setiap siswa yang mengakibatkan kemampuan konsep siswa yang satu berbeda dengan lainnya (Sucipta, Suastra dan Sadia, 2014: 8).

Penelitian ini juga memiliki beberapa kelemahan dimana aktivitas siswa tidak dapat dikontrol secara penuh. Dengan demikian, manajemen kelas menjadi point utama dalam perbaikan hasil pembelajaran. Fakta ini menunjukkan bahwa aktivitas yang baik dan terarah akan meningkatkan pemahaman konsep siswa (Yanti, 2019). Pola pembelajaran yang dilakukan merupakan sebuah "suasana" baru bagi siswa sehingga siswa tidak berpengalaman dalam menjalankan perannya. Dengan demikian, disarankan kepada peneliti selanjutnya atau pengajar agar membiasakan penggunaan model-model pembelajaran inovatif agar pengalaman belajar siswa terfasilitasi. Pengalaman akan terkait dengan capaian hasil belajar. Semakin banyak atau semakin lama waktu pengalamannya maka hasil belajar yang diperoleh cenderung semakin baik (Kocakaya \& Kotluk, 2016). 


\section{SIMPULAN}

Penelitian ini menemukan bahwa pemahaman konsep siswa meningkat menggunakan model pembelajaran beuristic vee pada materi fluida statis yang diterapkan pada siswa. Hal ini ditunjukkan dengan hasil analisis n-gain yaitu pada aspek menafsirkan sebesar 0,7 dengan kategori tinggi, aspek mengklasifikasikan 0,3 dengan kategori sedang, aspek menyimpulkan 0,6 dengan kategori sedang, aspek membandingkan 0,5 dengan kategori sedang dan aspek menjelaskan 0,2 dengan kategori rendah. Hasil analisis respon siswa terhadap model pembelajaran heuristic vee sebesar 92\% dengan kategori positif.

Berdasarkan pada lembar observasi heuristic vee, saran yang dapat disampaikan dalam penelitian ini yang telah dilakukan adalah sebagai berikut. 1) siswa kurang menjalankan prosedur pratikum. Oleh karena itu sebelum pembelajaran guru harus mampu menjelaskan petunjuk pelaksanaan praktikum, 2) suasana kelas terlalu ramai pada saat pratikum, sehingga pembelajaran tidak berjalan baik. Sebaiknya guru menggunakan pendekatan yang lain agar pembelajaran kelas berjalan lancar, 3) pembelajaran dengan model beuristic vee, kurang menggali pemahaman konsep pada aspek menjelaskan (kategori rendah). Sehingga harus menggunakan pendekatan atau treatment yang lebih inovatif, 4) guru hendaknya memberikan perhatian lebih dalam membimbing kelompok, agar semua siswa dapat bekerja sama dalam menyelesaikan permasalahan yang diberikan dengan baik.

\section{REFERENSI}

Anderson, W.L \& Krathwohl, R. D. (2010). Kerangka Landasan untuk Pembelajaran Pengajaran dan Asesmen (pp. 44-45). Yogyakarta: Pustaka Pelajar.

Creswell, J. W. (2009). Research Design: Qualitative, Quantitative, and Mixed Methods Approaches (3rd ed.). Thousand Oaks: SAGE Publications.

Evriani, E., Kurniawan, Y., \& Muliyani, R. (2017). Peningkatan Keterampilan Proses Sains (Kps) Terpadu Melalui Penerapan Model Pembelajaran Guided Inquiry Dengan Strategi Student Generated Respresentation (SGRS). Jurnal Pendidikan Fisika, 5(2), 119-125.

Hake, R. R. (1998). Interactive-engagement versus traditional methods: A six-thousand-student survey of mechanics test data for introductory physics courses. American Journal of Physics, 66(1), 64-74. https://doi.org/10.1119/1.18809

Kocakaya, S., \& Kotluk, N. (2016). Classifying the standards via revised Bloom's taxonomy: A comparison of pre-service and in- service teachers. International Journal of Environmental and Science Education, 11(18), 11297-11318.

Kurniawan, Y. (2018). The Enhancement of Consistency of Interpretation Skills on the Newton's Laws Concept. Jurnal Ilmu Pendidikan Fisika, 3(1), 28-30.

Muliyani, R. (2018). Signifikansi Discovery Learning Vs Guided Discovery Learning Terhadap Peningkatan Pemahaman Konsep. Gravity: Jurnal Ilmiah Penelitian Dan Pembelajaran Fisika, 4(1), 60-72. https://doi.org/10.30870/gravity.v4i1.3118

Nawati, I., Saepuzaman, D., \& Suhandi, A. (2017). Konsistensi Konsepsi Siswa Melalui Penerapan Model Interactive Lecture Demonstration Pada Materi Gelombang Mekanik. Jurnal Penelitian Pembelajaran Fisika, 8(1), 32-38. https://doi.org/10.26877/jp2f.v8i1.1334

Radiko, E., Kurniawan, Y., \& Muliyani, R. (2018). Identifikasi Pemahaman Konsep Siswa pada Materi Zat dan Wujudnya. Jurnal Ilmu Pendidikean Fisikea, 3(2), 52-54. 
Rahmawati, R. (2018). Pengarub Strategi Pembelajaran Heuristik Vee Terhadap Pemahaman Konsep Matematik Peserta Didik. UIN RAden Intan Lampung. https://doi.org/10.1017/CBO9781107415324.004

Sucipta, A. A. G. N., Suastra, I. W., \& Sadia, I. W. (2014). Konsep Fisika dan Sikap Ilmiah Siswa SMA e-Journal Program Pascasarjana Universitas Pendidikan Ganesha. E-Journal Program Pascasarjana Universitas Pendidikan Ganesha, 4(1), 1-12.

Suleyman, A. (2016). Analysis of analogy use in secondary education science textbooks in Turkey. Educational Research and Reviews, 11(19), 1841-1851. https://doi.org/10.5897/err2016.2984

Yanti, S. (2019). Upaya Meningkatkan Pemahaman Konsep Matematika Melalui Diskusi Kelompok Berbantuan Alat Peraga. Jurnal Pendidikan Matematika Dan IPA, 10(1), 63. https://doi.org/10.26418/jpmipa.v10i1.29658 